\title{
Pesquisa nas redes sociais da internet, à luz da perspectiva sistêmica
}

\author{
Research in internet social networks, \\ in light of the systemic perspective
}

Investigación en las redes sociales de internet, desde la óptica de la perspectiva sistémica

Anice Bezri Pennini

- Mestre em Comunicação Social pela Pontifícia Universidade Católica de Minas (PUC-Minas)

- $\quad$ Especialista em Marketing pela Fundação Getúlio Vargas (FGV)

- Graduada em Jornalismo pela PUC-Minas

- Co-organizadora do livro Compreendendo um campo de conhecimento: reflexões epistemológicas sobre a comunicação organizacional a partir de autores brasileiros (Curitiba, CRV, 2015)

- Jornalista e analista de pesquisa de mercado e opinião

- Experiência em comunicação organizacional e comunicação política

- E-mail: anicepesquisa@gmail.com

\section{Arabie Bezri Hermont}

- Doutora e mestre em Linguística pela Universidade Federal do Rio de Janeiro (UFRJ)

- Bacharel em Comunicação Social e licenciada em Letras pela Universidade Federal de Mi-nas Gerais (UFMG)

- Professora e pesquisadora do Programa de Pós-Graduação em Letras e Pedagogia da Ponti-fícia Universidade Católica de Minas Gerais (PUC-Minas)

- Coordenadora e pesquisadora do grupo de pesquisa "Estudos em linguagem e cognição" (Elinc) da PUC-Minas

- Co-organizadora dos livros Gerativa: (inter)faces de uma teoria (Florianópolis, Beconin, 2014) e Linguagem e cognição: diferentes perspectivas, de cada lugar um outro olhar (PUC-Minas, 2010)

- E-mail:arabie@uol.com.br 


\section{Resumo}

0 monitoramento de redes sociais na internet apresenta-se como uma possibilidade de pesquisa disponível aos comunicadores que atuam no contexto organizacional. Contudo, a análise das redes sociais não pode prescindir da reflexão sobre a convivência dos artefatos computacionais com o olhar dos pesquisadores envolvidos no processo. Este artigo analisa o monitoramento em redes sociais da internet à luz da perspectiva sistêmica, o que envolve a subjetividade dos pesquisadores, além da complexidade e da imprevisibilidade das dinâmicas sociais.

\section{PALAVRAS-CHAVE: COMUNICAÇÃO • REDES SOCIAIS DIGITAIS•INTERNET•ORGANIZAÇÕES•ANÁLISE.}

\section{Abstract}

Internet social networks monitoring is presented as a possibility of research available to communicators who work in the organizational context. However, the analysis of internet social networks cannot be done without considering the coexistence of computational technologies and the researchers' perspective. This paper analyzes the process of monitoring internet social networks in the light of the systemic perspective, which involves the subjectivity of the researchers, as well as the complexity and unpredictability of the social dynamics.

\section{KEYWORDS: COMMUNICATION・DIGITAL SOCIAL NETWORKS・INTERNET・ORGANIZATIONS・ANALYSIS.}

\section{Resumen}

El monitoreo de las redes sociales de internet se presenta como una posibilidad de búsqueda a disposición de los comunicadores que trabajan en el contexto de la organización. Sin embargo, el análisis de redes sociales no puede prescindir de la reflexión sobre la coexistencia de artefactos computacionales con la perspectiva de los investigadores involucrados en el proceso. Este artículo analiza el monitoreo de las redes de internet con enfoque sistémico, que implica la subjetividad de los investigadores, la complejidad y la imprevisibilidad de las dinámicas sociales. 
ANO 13 • NÚMERO 25 • 2은. 2016 - ORGANICOM

PESQUISA NAS REDES SOCIAIS DA INTERNET, À LUZ DA PERSPECTIVA SISTÊMICA

estudo de redes sociais em pesquisas de mercado e de opinião não é novo. Tais redes já eram objeto de pesquisa ao longo do século XX, a partir do entendimento de alguns pesquisadores de que os fenômenos sociais devem ser analisados em seu todo, como um conjunto de interações entre as partes. Entretanto, é notório que a internet e suas redes sociais amplificam a capacidade de conexão dos diversos atores sociais e aceleram a velocidade de disseminação de informações que afetam, entre outros saberes, a pesquisa de mercado no contexto dos processos de comunicação nas organizações.

Em tempos de sociedade midiatizada, em que os discursos e as tecnologias de comunicação são integrantes das tramas e dos processos nos mais diferentes campos de estudo, faz-se importante considerar as redes sociais da internet no rol de possibilidades de pesquisa das organizações públicas e privadas. Mas, nesse âmbito, em que as tecnologias computacionais apresentam grande relevância, faz-se também imprescindível problematizar a complexidade dos processos de pesquisa e a ação do pesquisador nesses estudos.

A perspectiva sistêmica, ancorada nas ideias de Ludwig von Bertalanffy (1973), ilumina conceitos importantes para uma análise do fenômeno contemporâneo, que é a pesquisa por meio das redes sociais da internet. Assim, a primeira seção deste artigo discorre sobre tal perspectiva e sobre a midiatização, conceito compreendido como um fenômeno que atravessa as sociedades, hodiernamente. A segunda seção aborda pensamentos e conceitos em torno da internet e das redes sociais, bem como suas imbricações com a comunicação no contexto organizacional. A terceira seção descreve e analisa a pesquisa por meio de monitoramento das redes sociais, sob as lentes da perspectiva sistêmica. Finalizamos o trabalho refletindo sobre a importância de se considerarem as possibilidades de pesquisa abertas pelas ciências da computação, mas sempre em uma visada que ilumina a convivência entre tecnologia computacional e o olhar do pesquisador, entendido como um ator social imbricado no processo de pesquisa.

\section{PERSPECTIVA SISTÊMICA COMO UMA ORIENTAÇÃO TEÓRICA}

Os métodos de investigação científica propostos pelo paradigma clássico, que se desenvolveu a partir do Renascimento, por volta do século XVI, foram o principal guia sobre o qual as pesquisas científicas e sociais se apoiaram até boa parte do século XX. Sob essa perspectiva, a racionalidade predomina, por meio de normatizações, que buscam reduzir os fenômenos sociais às suas dimensões mensuráveis.

Uma das ideias na qual essa perspectiva se ancora é a simplicidade, cujo pressuposto é dividir o todo em partes, a fim de se compreender mais profundamente cada parte, mesmo que tal processo desvincule o objeto de estudo de seu contexto, de suas relações com o todo. Outra noção prevalente no paradigma clássico é a estabilidade, que busca controlar e prever os fenômenos, buscando afastar a imprevisibilidade. E uma terceira marca do pensamento clássico é a objetividade, que preconiza a total abstenção do pesquisador de sua própria subjetividade, ou seja, de seus valores e crenças em relação ao objeto de estudo.

Apesar de ainda orientar muitas pesquisas na atualidade, os métodos ancorados no paradigma clássico ou tradicional das ciências, que influenciou e continua influenciando muitas pesquisas sociais aplicadas no âmbito da comunicação organizacional, têm convivido com outros pressupostos teóricos, como a perspectiva sistêmica, que considera a ideia do caos, da subjetividade e da complexidade.

Algumas das primeiras reflexões acerca do pensamento sistêmico foram publicadas ainda em meados do século XX, por Ludwig Von Bertalanffy (1973), que desenvolveu a teoria geral dos sistemas (TGS). 
Essa perspectiva impõe uma nova epistemologia da complexidade, que pode ser traduzida na formulação do construtivismo sistêmico-comunicacional, em que sistema, ambiente, complexidade, comunicação, diferença, observação, sentido, autopoiese, paradoxo e redução da complexidade são conceitos-chave que efetivamente superam os clássicos paradigmas da simplicidade, ancorados nos preceitos de causalidade linear, regulação externa, homogeneidade, ordem e reducionismo (CURVELLO, 2009, p. 95).

Percebe-se que, em vez da prevalência da ideia da simplicidade, os métodos de pesquisa sob a ótica sistêmica podem conviver com o pressuposto da complexidade, orientando um modo de abordar os fenômenos sociais que leva em consideração as contradições e os pensamentos não lineares, em vez de tentar excluí-los dos processos de conhecimento e investigação. Para Raquel Recuero (2011), na busca pela compreensão de um fenômeno, é necessário observar não apenas as partes desse fenômeno, mas as partes em interação. "Bertalanffy defendia que a perspectiva sistêmica é fruto de uma necessidade da ciência de compreender os fenômenos em sua totalidade e não mais como independentes uns dos outros" (RECUERO, 2011, p. 17). 0 pensamento complexo, portanto, considera a relação entre as partes. A instabilidade e a imprevisibilidade também têm sido consideradas nos estudos sob a orientação sistêmica, assimilando a compreensão de que o mundo não é ordenado. $E$, ainda, o entendimento da possibilidade de objetividade absoluta como pré-requisito aos estudos científicos vem dando espaço à ideia da subjetividade e intersubjetividade - uma noção de que os fenômenos são captados a partir do pesquisador ou de um conjunto de pesquisadores, que não têm como não inserir em suas observações suas próprias percepções do mundo. Assim, a perspectiva sistêmica funda-se no pensamento da complexidade, da instabilidade e da intersubjetividade.

Essas considerações são ainda mais complexificadas, à medida que se identifica, na contemporaneidade, um processo intenso de midiatização da sociedade, entendida neste artigo como um processo histórico construído pela articulação entre organizações sociais, tecnologias, entre outras instâncias, que tem produzido transformações no modo de presença dos atores sociais nas diversas práticas, na relação com outros indivíduos e organizações e na conformação da cultura de uma dada sociedade. Segundo Antonio Fausto Neto (2008, p. 92),

a convergência de fatores sociotecnológicos, disseminados na sociedade segundo lógicas de ofertas e de usos sociais produziu, sobretudo nas três últimas décadas, profundas e complexas alterações na constituição societária, nas suas formas de vida, e suas interações.

Para o autor, já não se trata mais de reconhecer a centralidade dos meios na tarefa de organização de processos interacionais entre os campos sociais, mas de entender que a própria constituição e o funcionamento da sociedade estão permeados pela cultura da mídia. Fausto Neto (2009) considera que a midiatização é uma realidade que se expande e se interioriza sobre a própria experiência humana, tendo como referência a lógica midiática. Assim, sob o viés da midiatização, todas as instâncias da vida social passaram a funcionar a partir da lógica midiática, o que não significa a onipotência dessa lógica, uma vez que não se pode desconsiderar a afetação mútua entre vida social e campo das mídias.

Enfatizamos que, neste artigo, entendemos os processos de interação midiatizada nos termos de Braga, em que interação não se limita à conversação, pois, segundo o autor, "a conversação enfatiza os processos de ida-e-volta, na troca entre interlocutores" (BRAGA, 2011, p. 68). Assim, o termo interação midiatizada, neste trabalho, afasta-se dos processos comunicacionais como um modelo dialógico, simétrico e recíproco de comunicação. Nesse ponto, cabe salientar a midiatização como processo interacional de referência, isto é, os processos de interação vêm sendo, cada vez mais, perpassados pela mídia - por suas lógicas e seus produtos midiáticos. 


\section{MONITORAMENTO DE REDES SOCIAIS NA INTERNET: UMA POSSIBILIDADE DE PESQUISA EM TEMPOS DE MIDIATIZAÇÃO}

Nesse contexto, as tecnologias digitais, a disseminação de smartphones e o crescente acesso à internet por parte da população brasileira promovem mudanças na comunicação e nos processos de formação de opinião. Em rede, as pessoas constroem narrativas e as fontes se multiplicam, em um processo em que todos podem receber e emitir informação. 0 que é publicado pode ser posto em questão, com potência para ser repercutido e reformulado.

Segundo Manuel Castells (2003, p. 116-117), "a internet foi acusada de induzir gradualmente as pessoas a viver suas fantasias online, fugindo do mundo real, numa cultura cada vez mais dominada pela realidade virtual". Mas, de acordo com o sociólogo, esse debate, bastante estéril, foi em grande parte comprometido por três limitações, quais sejam: i) ocorreu muito antes da difusão generalizada da internet e teve por base afirmações construídas a partir da observação de um número reduzido de experiência entre usuários pioneiros da internet, o que eleva a distância entre um pequeno grupo de indivíduos e o conjunto da sociedade; ii) desenvolveu-se na ausência de um corpo substancial de pesquisa empírica confiável sobre os usos reais da internet; e iii) foi construído em torno de questões bastante simplistas, como a oposição ideológica entre comunidade local harmoniosa de um passado idealizado e a existência do cidadão alienado e solitário na internet, muitas vezes associado ao estereótipo do nerd(Castells, 2003).

Neste artigo, consideramos que, se o relacionamento entre os sujeitos sociais se dá, em boa parcela, por meio da internet e de suas redes sociais, estas se constituem, então, em campo fértil para a pesquisa de mercado, com a finalidade de contribuir para o conhecimento dos comunicadores sociais.

Percebemos redes sociais da internet aos moldes de Danah Boyd e Nicole Ellison (2007), que as definem como serviços de web que permitem aos indivíduos, figuras públicas, organizações e governos construírem um perfil público ou semipúblico, dentro de um sistema conectado; que possibilitam a articulação dos perfis com uma lista de outros perfis, com os quais se compartilham conexões; e que permitem a cada perfil ver e mover-se por sua lista de conexões e pelas listas de outros perfis usuários. Por sua vez, pode-se entender o monitoramento de imagem de dada organização nas redes sociais da internet como a varredura de todos os termos, marcas e campanhas relacionados a tal organização, o que proporciona uma visão ampla sobre ela, por meio de registros feitos por consumidores, cidadãos, mídias em geral e todos os demais públicos de relacionamento. Vários processos tornam essa atividade de monitoramento organizada, com ações que visam à construção de um conhecimento novo ou à revisão de conhecimento já constituído, por meio da interação dos sujeitos sociais entre si e com as estruturas das redes sociais. Em suma, as tecnologias computacionais permitem hoje a realização do monitoramento das redes sociais da internet, onde se pode coletar e analisar posicionamentos de sujeitos sociais em relação a diversos temas e organizações.

É preciso ressaltar, contudo, que a internet permite-nos ver mais interações sociais do que jamais foi possível, e agora, nos deparamos com o excesso, em muitos casos. Mas é nesse cenário que precisamos trabalhar as informações e buscar sentido a partir de dados tão complexos (FRAGOSO; RECUERO; AMARAL, 2013). É preciso então, ter método para se trabalhar com a imensidão de dados e extrair conhecimento a partir deles. Entretanto, sejam quais forem os métodos e as ferramentas, as pesquisas mostram-se sujeitas, em alguma medida, ao olhar e às decisões dos pesquisadores, bem como vulneráveis à instabilidade e à complexidade próprias das dinâmicas sociais.

Assim, descrevemos a seguir, as principais funcionalidades e as maneiras mais recorrentes de se trabalhar com ferramentas computacionais de monitoramento das redes sociais, a fim de refletirmos sobre as potencialidades 
ANO 13 • NÚMERO 25 • 2으. SEM. 2016 • ORGANICOM

PESQUISA NAS REDES SOCIAIS DA INTERNET, À LUZ DA PERSPECTIVA SISTÊMICA

das tecnologias. Porém, apontamos, concomitantemente, a relevância da subjetividade, da imprevisibilidade e da complexidade envolvidas nos processos desse tipo de pesquisa.

De antemão, enfatizamos que há pelo menos três dimensões a serem consideradas nesses processos de monitoramento: i) o aparato computacional; ii) a capacidade analítica, que envolve dados de natureza quantitativa e de natureza qualitativa; e iii) a dimensão ética.

\section{O MONITORAMENTO DE REDES SOCIAIS E A PERSPECTIVA SISTÊMICA}

A dimensão relativa à tecnologia computacional deve ser pensada em duas vertentes: a capacidade de coletar e armazenar um volume satisfatório de postagens realizadas nas redes sociais da internet acerca das organizações, bem como a sofisticação tecnológica, que pode resultar em classificações automáticas das postagens, entre outros recursos que podem apoiar as análises, tais como os filtros do corpus da pesquisa por variáveis específicas.

A primeira etapa de um processo de monitoramento de redes sociais por meio de ferramentas desenvolvidas pelas ciências da computação consiste na configuração de palavras-chave a serem coletadas, ou seja, marcas, nomes de produtos ou temas relacionados ao universo da organização que se deseja monitorar. Faz-se importante mencionar que, quanto mais amplo o leque de palavras ou termos programados no monitoramento, mais complexo fica o processo, pois a coleta pode incluir grande volume de postagens que nada têm a ver com o objetivo da pesquisa.

Por isso, em princípio, tanto quanto possível, apenas a marca em si deve ser monitorada e não a totalidade de temas a ela vinculados. Por exemplo, se estamos monitorando uma organização que atua na área de alimentação, devemos monitorar o nome da organização e/ou de suas marcas mais conhecidas. Se monitorarmos o nome dos alimentos, a coleta automática incluirá as postagens cujo conteúdo trata de cada um dos alimentos, mas em contextos os mais diversos possíveis, que pouco ou nada têm a ver com a marca.

Cumpre enfatizar neste ponto que a própria definição de palavras-chave, por si só, já inclui a subjetividade do pesquisador na base da pesquisa. E mais, mesmo cuidando para que o conjunto de postagens coletadas seja pertinente ao objetivo do monitoramento, não há como apartar a imprevisibilidade da própria coleta, pois muitas vezes, a marca de uma organização é um nome próprio ou palavra comum o suficiente para aparecer relacionada em outros contextos, que não dizem respeito ao objetivo da pesquisa. Como exemplo para essa situação, pode-se citar um eventual monitoramento da marca de sandálias Havaianas, já que a palavra pode remeter a diversas menções que nada têm a ver com a marca. Outro exemplo é um monitoramento do banco Caixa Econômica Federal, frequentemente referido somente como Caixa. Assim, logo após as primeiras postagens armazenadas pelos computadores, recomenda-se começar o trabalho do pesquisador, excluindo do monitoramento as postagens que contiverem as palavras-chave determinadas previamente, mas que não disserem respeito à organização monitorada, para que o processo de aprendizado de máquina abarque o contexto desejado em torno das palavras-chave.

Os recursos de automação mais recorrentes nas ferramentas de monitoramento são a classificação do teor do sentimento dos posts em relação ao objeto de investigação, a classificação dos temas a que se refere cada postagem e a capacidade de classificar o tipo de emissor das postagens. 
ANO 13 • NÚMERO 25 • 2으. SEM. 2016 • ORGANICOM

PESQUISA NAS REDES SOCIAIS DA INTERNET, À LUZ DA PERSPECTIVA SISTÊMICA

A classificação automática do sentimento das postagens, também chamada de valência ou polaridade, conforme a ferramenta de monitoramento, constitui-se em poderoso legado das ciências da computação para os estudos sociais, pois permite que grande volume de postagens seja classificado com conteúdo positivo, neutro ou negativo a determinada organização. Há ferramentas que admitem a classificação do sentimento de uma mesma postagem como mista, já que uma mesma manifestação de um mesmo emissor pode ser interpretada em parte como positiva e em parte como negativa. Entretanto, em geral, a automação das ferramentas ocorre somente a partir de determinado número de postagens marcadas como positivas, neutras ou negativas pelo pesquisador. Ou seja, as máquinas aprendem com a análise humana se determinado teor de comentário em redes sociais é favorável, neutro ou desfavorável ao objeto da pesquisa. Exemplos recentemente observados nesse âmbito foram postagens em torno do processo de impeachment da ex-presidente Dilma Rousseff, ocorrido entre abril e agosto de 2016. Imagine-se um monitoramento sendo realizado por uma organização de grande porte, que incluísse em suas palavras-chave os termos economia e um setor de atuação da empresa, como, por exemplo, caminhões. Postagens sobre o contexto do impeachment apareceriam nesse monitoramento, já que conteúdos nas redes sociais especulando sobre a economia brasileira em um cenário de impeachment foram abundantes nesse período, associadas a diversos tipos de indústrias, inclusive a de veículos pesados. Uma mesma postagem com conteúdo favorável ao impeachment, por exemplo, poderia ser classificada com valência positiva, negativa ou neutra, dependendo da visão do pesquisador sobre os interesses e as expectativas da organização em relação ao tema. Há que se considerar ainda, que existem momentos em que os atores sociais fazem postagens confusas ou contraditórias nas redes sociais, o que demanda uma análise qualitativa da postagem, a fim de se compreender como classificá-la em relação à organização demandante do monitoramento.

E, mais que subjetividade, no caso de grandes organizações, há que se falar da intersubjetividade na classificação das postagens, já que, muitas vezes, observa-se que há necessidade de um grupo de analistas trabalharem no mesmo monitoramento, dada a grande quantidade de postagens relativas a uma mesma organização. Mesmo que seja estabelecido um guia para que o conjunto de analistas sociais saiba como classificar cada uma das menções de acordo com o sentimento, o número de variáveis que podem intervir nesse processo é tal que não há como barrar a subjetividade de cada analista.

Aquilo que se fala nas redes sociais acerca das organizações, sobretudo as de grande porte, varia sobremaneira, conforme 0 contexto em que ela se insere. Dessa forma, a classificação das postagens em temas é uma das etapas mais sensíveis de um monitoramento em redes sociais. Por exemplo, se for uma instituição governamental, pode-se agrupar as menções pelos temas "educação", "saúde", "cultura" etc. Se for uma organização privada, as postagens podem ser agrupadas em temas como "imagem institucional", "produtos", "executivos da organização" etc. A classificação automática se dá no momento em que os softwares conseguem apreender que determinada conjunção de palavras ou termos que aparecem em uma mesma menção ou um mesmo conteúdo refere-se a cada tema. Mas, assim como na classificação de sentimentos, a interpretação automática de temas só ocorre após os pesquisadores analisarem uma amostra satisfatória de postagens das redes sociais. Nesse âmbito, há muitas fronteiras borradas, em que a atuação do pesquisador é imprescindível e altamente subjetiva, já que uma mesma postagem pode conter referências a mais de um tema. Em um monitoramento para uma empresa de energia elétrica, por exemplo, postagens que tratam sobre o impacto economicamente negativo para a produção industrial em consequência de falta de energia, causada por deficiência de infraestrutura de geração, transmissão ou distribuição de energia elétrica, podem ser classificada com o tema "impactos socioeconômicos" ou com o tema "infraestrutura". Nesse caso, há que se analisar qual enquadramento é predominante nas mensagens; do contrário, tem-se muitas postagens classificadas como tema misto, que pouco esclarecem no momento das análises.

0 tipo de emissor também é uma potencialidade oferecida por muitas ferramentas de monitoramento. Há como classificar os emissores das mensagens em redes sociais em diferentes categorias, conforme o objetivo e os perfis que se manifestam sobre 
o objeto estudado. Esses podem ser classificados em diversas categorias, tais como: mídias, figuras públicas, celebridades, cidadãos ou clientes da organização em estudo. Novamente, o pesquisador é chamado a tomar decisões. Imagine-se uma postagem feita por um perfil no Twitter de um comentarista de programa esportivo de tevê. É uma postagem passível de ser classificada na categoria "mídias". Porém, se o comentarista for um ex-jogador de futebol que já era famoso antes de ser comentarista, essa postagem também poderia ser classificada em "celebridade". Nesse âmbito, cabe comentar sobre as dinâmicas de interações midiatizadas, em que as mídias consideradas por muitos brasileiros como referência (jornais, revistas, rádios e canais de televisão mais longevos e conhecidos do país), também ocupam espaço de relevância nas redes da internet. E muitos atores sociais se valem de compartilhamentos de notícias veiculadas nas mídias de referência ou de menções a essas notícias para expressar-se nas redes digitais. Essas interações midiatizadas são facilmente percebidas nos monitoramentos de redes sociais, onde se observa que a mídia se integrou às rotinas de outras instituições, como política, economia e trabalho. Nesses casos, os pesquisadores devem decidir como irão classificar os emissores: como cidadãos comuns, que baseiam sua opinião em determinada mídia, ou se a postagem será classificada como sendo de autoria da imprensa ou mídia.

Os atores sociais que comentam sobre uma organização também podem ser classificados como apoiadores ou detratores em relação a ela. Mas, só a partir de uma amostra classificada pelo olho humano (e esse número varia conforme a ferramenta) é que se consegue começar a fazer a classificação automática das postagens.

E, mesmo após todas as classificações entrarem em modo automático (sentimentos, temas, tipo de emissor etc.), a análise do pesquisador continua imprescindível. Como o mundo social é dinâmico, fluido e imprevisível, não há como simplesmente acionar a classificação automática e deixar que os algoritmos façam o trabalho por si só, por muito tempo. Dependendo da quantidade de postagens coletadas e do contexto no qual se insere uma organização, o trabal ho do analista deve ser constante, já que novos temas, crises e sujeitos interagentes podem fazer-se presentes nas redes sociais, a qualquer momento.

Além das possibilidades de classificação automática, algumas ferramentas de monitoramento oferecem outros recursos que auxiliam o trabalho dos pesquisadores ao tratarem o grande volume de dados que são registrados nas redes sociais da internet. Há, por exemplo, filtros que permitem extrair informações de postagens apenas com determinado sentimento (positivo, negativo ou neutro), com determinado tema ou comentários advindos apenas de determinados tipos de emissores. Há também ferramentas que apresentam outros recursos, tais como nuvens de palavras, em que a frequência de determinados termos no contexto do monitoramento é mensurada pelo tamanho das palavras/termos nas nuvens. Cabe mencionar, também, que há ferramentas que mesclam os dados obtidos nas redes sociais com informações oriundas de outras bases de dados, tais como informações sobre o relacionamento das organizações com seus clientes, também conhecidas como customer relationship management (CRM). Contudo, todas essas decisões de processamento de dados e extração de informações partem de decisões dos pesquisadores.

Realizada a coleta e utilizados os recursos de classificação e filtragem, é preciso trabalhar a análise, já que os dados geram conhecimento somente a partir do trabalho analítico. E, se no momento de coleta e classificação o corpo de dados a ser analisado é separado de acordo com o sentimento, o tema e o tipo de emissor, no momento da análise, há que se estabelecer um sentido ao conjunto das informações.

Ou seja, a análise que gera conhecimento e ação oportuna às organizações não se dará com a análise profunda de cada uma das partes, embora inclua essa análise também. Mas ocorrerá a partir da extração de sentido do todo, da percepção da complexidade do tecido social e do (des)equilíbrio de forças. Para tanto, os relatórios a serem elaborados a partir do monitoramento das redes sociais devem incluir dados tanto de natureza quantitativa, como de cunho qualitativo. Certamente, para a imagem de 
uma organização, um grande volume de postagens com conteúdo positivo e/ou neutro é melhor do que um grande volume de postagens de natureza negativa. Contudo, há que se analisar o teor qualitativo do conteúdo. Por exemplo, há temas efêmeros, que causam grande alarde em um dia, mas tendem a ter baixo compartilhamento no dia seguinte. Em geral, são temas que não se sustentam nos fatos ou se referem a piadas que se desgastam rapidamente. Por outra via, há temas que surgem nas redes sociais da internet de maneira discreta, com baixo volume de compartilhamento, mas que vão crescendo paulatinamente em relação ao conjunto de postagens, justamente por agregarem, a cada dia, mais informações que os sustentam ou por serem compartilhados por fontes que gozam de elevada credibilidade no meio social em que se insere a organização.

Há que se analisar ainda se as informações, sejam de conteúdo positivo ou negativo, estão partindo de mídias ou figuras públicas que há muito já são declaradamente detratoras ou apoiadoras da organização em estudo ou se são novos interagentes a comentarem sobre essa organização.

Outro aspecto a ser observado é a relação das informações obtidas por meio das redes sociais da internet com eventos exógenos a esse ambiente. A sociedade que se manifesta nas redes sociais, é, muitas vezes, apenas uma parcela dos públicos de relacionamento de uma organização. Assim, a análise das informações nas redes sociais associadas a outros eventos (declarações, campanhas, ocorrências, atuação dos concorrentes etc.) enriquece as conclusões da pesquisa.

Em síntese, o monitoramento nas redes sociais não deve ser tomado como algo apartado das outras formas de observação da imagem das organizações no contexto em que elas se inserem. Por isso, mais uma vez, enfatizamos que nada substitui a capacidade analítica do sujeito social responsável por extrair conhecimento do monitoramento das redes sociais, em um processo de junção e elaboração conjunta com outras fontes de informação.

A própria periodicidade das análises e da elaboração dos relatórios é uma escolha subjetiva e influencia tanto a análise qualitativa como os dados quantitativos. Se tivermos como ponto pacífico que o fluxo de informações que aporta nas redes sociais é contínuo e que, em determinado momento do dia ou da semana, há um corte para realização das mensurações, pode-se dizer que há interferência da decisão dos pesquisadores sobre o percentual de postagens positivas e/ou neutras e/ou negativas acerca de dada organização. Enfim, dependendo da hora, do dia ou da semana, as análises advindas das redes sociais da internet poderão mostrar diferentes recortes da mesma organização. A subjetividade, portanto, continua em cena, a despeito de toda a tecnologia computacional disponível para se processar milhões de informações nas redes sociais da internet.

Há ainda que se mencionar as questões éticas no trabalho de monitoramento das redes sociais, questões essas que estão em constante debate e nem sempre encontram consenso, principalmente no que se refere ao direito à privacidade de quem publica nas redes sociais da internet. Um exemplo da falta de consenso: há mais de um ano, o Facebook - a rede social com maior número de usuários no planeta - passou a impedir que as ferramentas de coletas de postagens captassem informações advindas de perfis particulares (usuários comuns da rede). Desde maio de 2015, as ferramentas coletam postagens feitas por usuários comuns somente quando estes se manifestam em páginas públicas, tais como as fanpages das mídias, de organizações públicas e de empresas privadas em geral. A rede Twitter, por sua vez, não fez tal restrição.

Frisamos que não se quer, neste artigo, tratar de normas ou lançar ideias para um suposto código de conduta ética para os comunicadores organizacionais que trabalham ou que vierem a trabalhar com informações advindas das redes sociais da internet. Esse é um trabalho de monta, que demanda estudo específico. 0 que se pretende é tão somente ressaltar a importância desse debate de conduta ética em uma sociedade, como é o caso da brasileira, em crescente processo de 
midiatização, em que clientes, empregados ou mesmo dirigentes de uma organização podem se manifestar em rede digital acerca de dada organização ou contexto e, sem desejar, podem vir a ter seus comentários replicados ou monitorados. Esse é um debate que, claramente, envolve os comunicadores que atuam em ambiente organizacional.

\section{CONSIDERAÇÕES FINAIS}

Em um ambiente comunicacional complexo, em que o tecido social é atravessado por informações que se disseminam e se amplificam nas redes sociais da internet, vê-se que as tecnologias computacionais apresentam às organizações novas possibilidades de conhecimento da opinião e das tendências de seus públicos de relacionamento. Mas, embora as interações e toda a produção de conhecimento possibilitada pelos artefatos tecnológicos da computação nos digam muito sobre a imagem de determinada organização nas mídias, somente com a atuação do pesquisador sobre o conjunto de informações coletadas pelas máquinas é que se poderá obter uma análise adequada.

E, nesse âmbito, está incluída a visão de mundo do sujeito social que trabalha com a pesquisa, tanto quanto a complexidade do tecido social em que se inserem as organizações contemporâneas, bem como a imprevisibilidade própria das dinâmicas sociais, conformando um ambiente que se afasta da perspectiva de pesquisa científica linear, ordenada e objetiva.

\section{REFERÊNCIAS}

BERTALANFFY, Ludwig Von. Teoria geral dos sistemas. Petrópolis, RJ: Vozes, 1973.

BOYD, Danah; ELLISON Nicole B., Social network sites: definition, history and scholarship. Journal of Computer-Mediated Communication, article 11, 2007.

BRAGA, José Luiz. Constituição do campo da comunicação. Verso e Reverso, São Leopoldo, Unisinos, v. XXV, n. 58, p. 62-77, jan.-abr. 2011.

CASTELLS, Manuel. A galáxia da internet. Rio de Janeiro: Zahar, 2003. p. 116-117.

CURVELLO, João J. A. A perspectiva sistêmico-comunicacional das organizações e sua importância para os estudos da comunicação organizacional. In: KUNSCH, Margarida M. Krohling (org.). Comunicação organizacional. Vol. 1 - Histórico, fundamentos e processos. 1. ed. São Paulo: Saraiva, 2009. p. 91-105.

FAUSTO NETO, Antonio. Fragmentos de uma "analítica" da midiatização. Matrizes, São Paulo, n. 2, p. 89-105, abr. 2008 . Epistemologia do ziguezague. In: SEMINÁRIO DE EPISTEMOLOGIA E PESQUISA EM COMUNICAÇÃO, I, Unisinos, maio 2009. Anais... São Leopoldo: Unisinos, 2009. p. 79-93.

FRAGOSO, Suely; RECUERO, Raquel; AMARAL, Adriana. Métodos de pesquisa para internet. Porto Alegre: Sulina, 2013. RECUERO, Raquel. Redes sociais na internet. Porto Alegre: Sulina, 2011.

Artigo recebido em 07.08.2016 e aprovado em 09.10.2016. 